\title{
Inflammation in the lungs of rats after deposition of dust collected from the air of wool mills: the role of epithelial injury and complement activation
}

\author{
K Donaldson, Geraldine M Brown, D M Brown, Joan Slight, R T Cullen, R G Love, \\ C A Soutar
}

\begin{abstract}
In a previous study assessing respiratory symptoms in individuals employed in wool textile mills in the north of England relations between symptoms of chronic bronchitis, breathlessness and wheeze, and rhinitis and current exposure to airborne mass concentration of dust were shown. As preliminary steps in defining the potential hazard associated with dust from the air of wool mills the ability of inspirable dust, collected from the air of wool textile mills, to cause inflammation when injected into the lungs of rats was determined. Dusts were collected from the beginning of wool processing (opening) in one factory and from the middle (combing) and late (backwinding) stages of the process in two other factories. Ability of the dusts to cause inflammation was assessed by instillation into the lungs of rats followed by bronchoalveolar lavage. All the dusts caused some inflammation which peaked on day 1 and did not persist beyond one week. A distinctive aggregation response of mononuclear cells in the lavage, however, had a different time course, peaking at day 7 . An attempt was made to determine how the wool mill dusts caused inflammation and experiments showed that the dusts themselves had no inherent chemotactic activity but that they did have a pronounced ability to generate chemotaxins in serum and so could activate complement in lung fluid. In addition, dust collected from ledges in the mills had the ability to injure epithelial cells in vitro which could also contribute to inflammation. A role for endotoxin in the inflammatory activity of the dusts was not discounted and a leachate of the dust had the ability to cause inflammation when injected into the lungs of rats. Wool mill
\end{abstract}

Institute of Occupational Medicine, Edinburgh EH8 9SU

$\mathrm{K}$ Donaldson, Geraldine $\mathrm{M}$ Brown, D M Brown, Joan Slight, R T Cullen, R G Love, C A Soutar dust is likely to be a complex mixture of materials and these experiments represent a preliminary approach to understanding the biological activity of the whole unfractionated dust and further studies are in progress to define more accurately the toxic material(s) in the dust.

The Institute of Occupational Medicine studied the prevalence of respiratory symptoms in individuals employed in wool textile mills in the north of England. ${ }^{1-3}$ Clear relations have been shown between current exposures to airborne mass concentrations of inspirable dust in these mills and the prevalence of symptoms, such as chronic bronchitis, breathlessness and wheeze, rhinitis, and conjunctivitis, suggesting that inhalation of the dusts causes inflammation in the upper and lower respiratory tract. ${ }^{1}$ Complementary studies of the lung functional and radiographic effects of occupational exposure to wool mill dusts have also been carried out. ${ }^{3}$ As an adjunct to the epidemiological studies on symptoms, respirable dust was collected from the air of selected wool mills with the objective of testing the dusts in rat lung to measure their ability to cause inflammation. Similar in vitro studies have been carried out on other organic dusts associated with bronchitic symptoms. These have shown evidence of chemotactic activity, complement activating activity, and epithelial injuring activity in cotton dust components ${ }^{45}$ and chemotactic activity, complement activating activity, and ability to induce neutrophil chemotaxin release from macrophages in grain dust. ${ }^{6}$

The present paper reports preliminary work aimed at defining the biological activity of unfractionated respirable wool mill dust and describes the leukocyte responses, assessed by bronchoalveolar lavage, to the deposition of the dust or soluble factors thereof in the lungs of laboratory rats. The ability of the wool mill dust to activate complement and cause epithelial injury has also been shown and this may explain, in part at least, how wool mill dust engenders inflammation in the lung experimentally and causes inflammation of the respiratory tract in exposed workers. 


\section{Materials and methods}

RATS

Syngeneic, PVG rats, SPF maintained, were obtained from the Institute of Occupational Medicine breeding unit.

DUSTS

Dust samples were collected using IOM static inspirable dust samplers from the air of three mills chosen to represent the start (S), middle (M), and end (E) of the industrial processing of wool in the vicinity of opening (carpet yarn), combing (worsted process), and backwinding (carpet yarn) processes respectively from three mills in west Yorkshire. Each process was sampled in a different mill (in other IOM reports these are referred to as mills 15,4 , and 11 respectively). These samples, on filters, were sent by post to the Institute of Occupational Medicine where they were stored at $-20^{\circ} \mathrm{C}$ for up to six months before use. Samples from each mill were removed from the filter with a brush, pooled, and coarse material was removed by hand. The remaining pooled samples of fine dust were mixed overnight on a rotating mixer to ensure homogeneity and stored at $-20^{\circ} \mathrm{C}$. Samples of the three wool dusts were then irradiated at 150 $\mathrm{KRad}$ at the National Engineering Laboratory, East Kilbride, to reduce the number of live contaminating fungal spores and bacteria. Non-irradiated samples of each dust were retained as a reference. Titanium dioxide $\left(\mathrm{TiO}_{2}\right.$; rutile form; Tioxide Limited, Stockton-on-Tees) was used as an inert control dust.

\section{INTRATRACHEAL INJECTION}

Wool dusts and $\mathrm{TiO}_{2}$ were prepared at $5 \mathrm{mg} / \mathrm{ml}$ in sterile phosphate buffered saline (Gibco, Paisley) and $0.5 \mathrm{ml}(2.5 \mathrm{mg})$ aliquots were introduced into the lungs of groups of three rats. Instillation was carried out by surgical exposure of the trachea in anaesthetised rats followed by direct injection of dust suspension into the lung through a small incision in the trachea; the overlying skin was then closed with metal clips. Animals were conscious within two minutes and completely recovered within hours; no animal died after injection of the dusts. Rats were kept for one, three, seven, or 14 days at which point the experimental group was killed and the bronchoalveolar space lavaged.

\section{BRONCHOALVEOLAR LAVAGE}

To assess inflammation, three rats were killed by Nembutal (Ceva, Watford) overdose and the lungs were lavaged with $4 \times 8 \mathrm{ml}$ volumes of saline at $37^{\circ} \mathrm{C}$. The cells were concentrated by centrifugation, counted, and the differential count carried out on a May-Grunwald Giemsa-stained cytospin (Shandon Runcorn) preparation. From these, the totals of each cell type were calculated. Data is presented as mean and standard error of macrophages, neutrophils, and? lymphocytes.

SOLUBLE PRODUCTS (LEACHATE) FROM WOOL MILIC DUST

A leachate was prepared, using sterile pyrogen frees saline, from dust $M(5 \mathrm{mg} / \mathrm{ml})$ by mixing overnight in a rotating mixer; the particulate fraction was centrifuged out to yield the soluble components, or leachate, of the dust. This was injected as $0.5 \mathrm{mP}$ (equivalent to $2.5 \mathrm{mg}$ of dust) as described above.

\section{ENDOTOXIN}

Endotoxin (Gibco) was injected intratracheally into $\frac{\Phi}{S}$ the lungs of a group of three rats as $2.5 \mu \mathrm{g}$ in $0.5 \mathrm{ml} \mathrm{of}$ saline and the lungs lavaged three days later.

ACTIVATION OF CHEMOTAXINS IN SERUM BY

TREATMENT WITH WOOL DUST

Rat serum $(10 \%)$ was treated with wool dust $M^{\supset}$ $(1 \mathrm{mg} / \mathrm{ml})$, mixed in a water bath at $37^{\circ} \mathrm{C}$ for $30 \mathrm{D}$ minutes, and then heat inactivated $\left(56^{\circ} \mathrm{C}\right.$ for $30^{\circ}$. minutes). Previous studies have shown that treat $-\overrightarrow{0}$ ment of serum with particulate in this manner causese activation of complement to yield the chemotactic anaphylatoxin $\mathrm{C5a}^{7}$

\section{CHEMOTAXIS}

Chemotaxis was carried out using conventionato Blindwell chambers. Zymosan activated serum $\left(200 \frac{\mathrm{D}}{2}\right.$ $\mu \mathrm{l})$ or serum treated with wool dust, at $5 \%$, or leachate of wool mill dust was placed in the lower compartment of a Blindwell chamber and a $5 \mu \mathrm{m}$ pore filter (Nuclepore, Pleasanton, California) placed on top. In the upper compartment were placed $400 \mu \mathrm{l}\left(6 \times 10^{5}\right.$ cells $)$ of control bronchoalveolar lavage cells $\left(>95 \%\right.$ macrophages) $\frac{3}{\sigma}$ Blindwell chambers were then incubated at $37^{\circ} \mathrm{C}$ in $5 \% \mathrm{CO}_{2}$ for 3.5 hours. Filters were removed and stained with Diff-Quik and the number of migrated cells assessed by high power light microscopy Results are expressed as migrated cells/high power field (mean of five fields on two filters-that is $\frac{D}{0}$ $\mathrm{n}=10$ ). To test for chemokinesis a modified "checkerboard" analysis was performed with $5 \% \mathrm{~N}$ zymosan activated serum in both the upper and lowern compartments.

ASSAY OF INJURY TO EPITHELIAL CELLS IN VITRO The assay is that described previously. ${ }^{8}$ Briefly, cells of the alveolar epithelial cell line A549 wer prelabelled with ${ }^{51} \mathrm{Cr}$ (Amersham International Amersham) by incubating overnight in microtitre plate wells at $5 \times 10^{4}$ in $100 \mu$ l of MEM $+10 \%$ feta calf serum (Gibco, Paisley). To these plates were added varying dilutions of a leachate prepared, as described above, from fine ledge dust obtained from wool mills $M$ and $S$, to a total volume of $200 \mu \mathrm{l}$ Ledge dust was used because all the respirable 
material was used for the above experiments and ledge dust was therefore the best alternative to airborne dust; it was stored as for the airborne dust. In some experiments dust was leached into lung lavage fluid as well as medium to determine whether leaching was likely to occur in the milieu of the lung. After four hours of incubation at $37^{\circ} \mathrm{C}$ in $5 \% \mathrm{CO}_{2}$ the wells were sampled to obtain the counts released from lysed (dead) cells and counts within cells which had detached from the substratum.

\section{STATISTICAL ANALYSIS}

Results were analysed by analysis of variance and differences between treatment groups tested for statistical significance using a Student's $t$ test.

\section{Results}

\section{BRONCHOALVEOLAR LEUKOCYTE RESPONSE TO}

DEPOSITION OF WOOL DUST

Figure 1 shows the kinetics of the bronchoalveolar
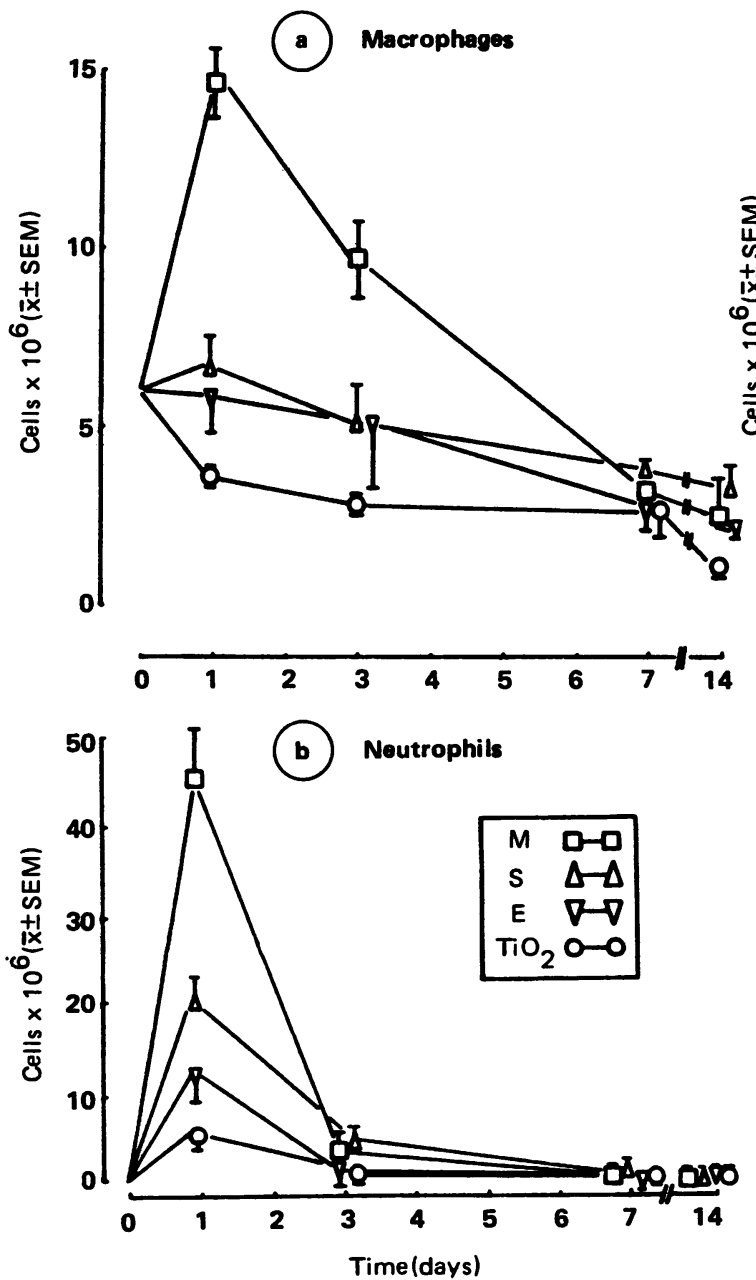

leukocyte response to the injection of $2.5 \mathrm{mg}$ of dust from three different wool mills and $\mathrm{TiO}_{2}$. With two of the dusts the macrophage counts did not increase substantially, although with dust $S$ the numbers were significantly higher than the $\mathrm{TiO}_{2}$ response. In the case of dust $M$, however, there was pronounced recruitment on days 1 and 3. Neutrophil response shows clearly that all four dusts caused some degree of inflammation on day 1 with the following order of activity: $\mathrm{M}>\mathrm{S}>\mathrm{E}>\mathrm{TiO}_{2}$. By day 3 all dusts were producing low levels of neutrophil influx and by days 7 and 14 levels approached 0 the norm for control rats.

The lymphocyte reponse was in keeping with the general pattern of the leukocyte response but it was noticeable that by day 14 the lymphocytes present in wool exposed lung exceeded those present in $\mathrm{TiO}_{2}$ exposed lung.

The total number of cells present in the lavage is not completely reflected in the free cells described above in view of the fact that a small proportion of
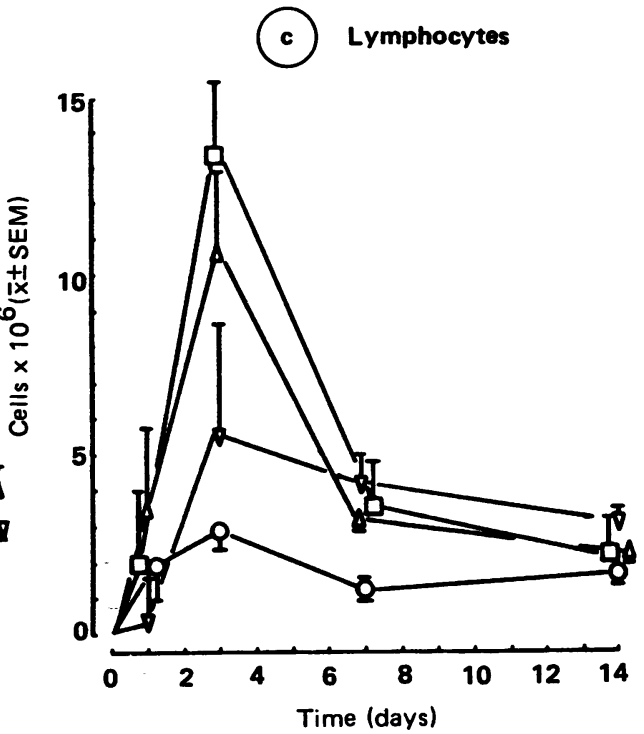

Figure 1 (a) Mean number of macrophages lavaged from lungs of three rats injected with $2.5 \mathrm{mg}$ of indicated dusts; bars represent SEM. Significant $(p<0.05-0.01)$ increases compared with $\mathrm{TiO}_{2}$ with following: one day $M, S$; three days M. (b) Mean number of neutrophils lavaged from lungs of three rats injected with $2.5 \mathrm{mg}$ of indicated dusts; bars represent SEM. Significant $(p<0.05-0.01)$ increases compared with $\mathrm{TiO}_{2}$ for following: one day $M, S$; three days $M, S$. (c) Mean number of lymphocytes lavaged from lungs of three rats injected with $2.5 \mathrm{mg}$ of indicated dusts. Significant increases compared with $\mathrm{TiO}_{2}$ : three days $M, S$; seven days $S, E$. 
cells were bound up in cell clumps (see below).

\section{CELL CLUMPS}

Populations of cells obtained from the bronchoalveolar space of rats treated with wool dust contained unusual aggregates (or clumps) of cells. These clumps often seemed to be gathered around particles of wool mill dust visible by light microscopy but sometimes there was no particle clearly visible at the centre of the aggregate. These cells were predominantly mononuclear and often comprised layers of cells, some making contact with the particle but some making contact with other cells only. The appearance of these clumps did not coincide with the peak of inflammation (one day) but peaked between days 3 and 14 (seven days in our time course) (fig 2).

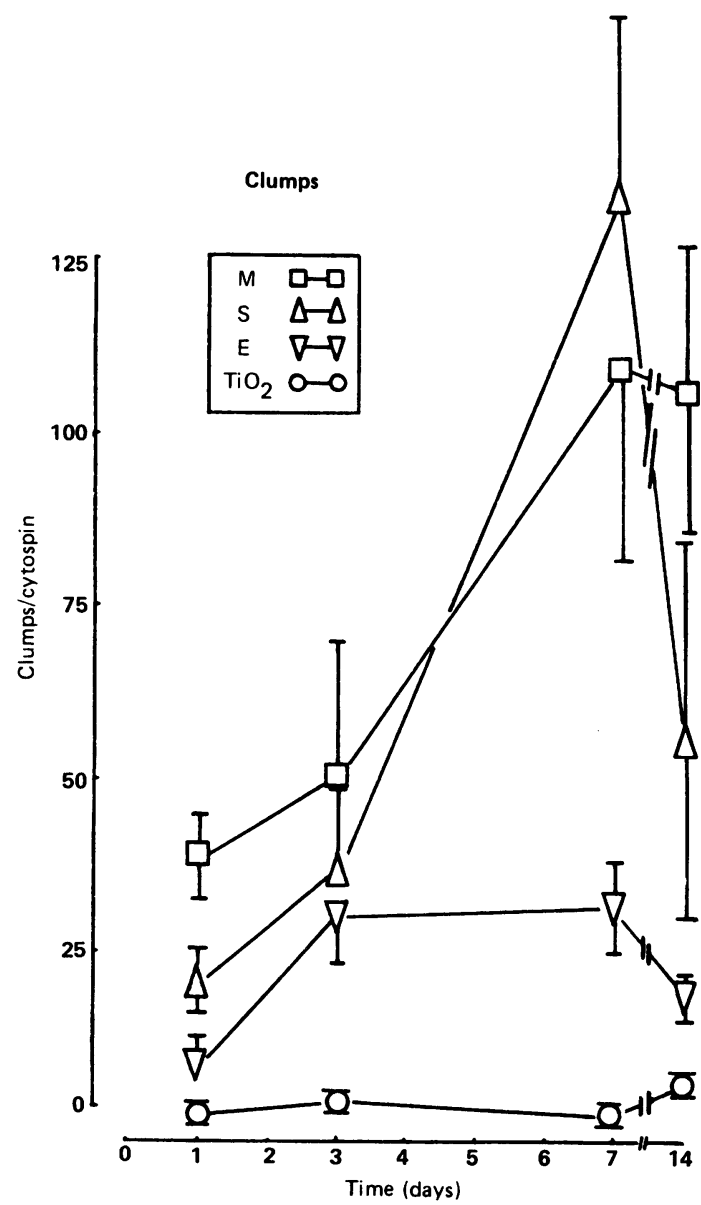

Figure 2 Mean number of clumps per cytospin preparation of bronchoalveolar cells collected from three rats injected with $2.5 \mathrm{mg}$ of indicated dusts. Significantly $(p<0.05-0.001)$ increased numbers of clumps compared with $\mathrm{TiO}_{2}$ at following: one day $M, S$; three days $M$; seven days $M, S, E$; and 14 days $M, S, E$.
In all cases the number of aggregates had fallen $\stackrel{\varnothing}{\circ}$ substantially by day 14 except in the case of dust $M$ where the number remained high.

ROLE OF DIFFUSIBLE COMPONENTS IN THE WOOL DUST To test whether soluble components of wool dust were diffusing from the particles and causing inflammation, a particulate free leachate of dust $M(2.5 \mathrm{mg}$ of dust equivalent) was injected intratracheally into the lungs of rats and the rats lavaged three days later. As shown in table 1 some, but not all, of the inflammatory potential of whole wool dust could be reproduced with a particle free extract, strongly suggesting that soluble factors do have a role in $\exists$ causing inflammation. It was noticeable, however, that these diffusible components did not have the is ability to produce clumps.

Endotoxin $(2.5 \mu \mathrm{g})$ caused only moderate neutrophil recruitment and had little effect on macrophage $\stackrel{\circ}{I}$ recruitment (table 1).

EFFECTS OF IRRADIATION ON THE ABILITY OF WOOL DUST TO CAUSE INFLAMMATION Irradiation of wool mill dusts did not substantially $\varnothing$ affect their ability to generate inflammation in rat lungs. The irradiated dusts did, however, cause slightly more macrophage and neutrophil recruitment than the non-irradiated: results given are $\bar{x}$ (SD) of cells $\times 10^{6}$ for groups of three rats, three days after instillation-non-irradiated macrophages 4.6 $(0.5)$, neutrophils $3.7(0.7)$; irradiated macrophages $7 \cdot 8(1 \cdot 1)$, neutrophils $5 \cdot 1(0 \cdot 9)$.

\section{GENERATION OF CHEMOTAXINS BY WOOL DUST}

As shown in table 2 the leachate of pooled dust $M$ had no chemotactic activity so precluding the possibility that products released by the wool dust itself were directly attractive to leukocytes and could contribute to the recruitment of inflammatory cells. As shown in table 3 , however, wool dust was highly active in generating chemotaxins in rat serum and, by analogy, 욱 in alveolar fluid. The modified "checkerboard" $>$ analysis (table 3) showed that although some

Table 1 Inflammation assessed by brochoalveolar lavage three days after intratracheal instillation of soluble components derived from wool dust $M$ and by endotoxin. Significantly $(p<0.001)$ increased numbers of both macrophages and neutrophils with all treatments compared with saline

\begin{tabular}{lcl}
\hline & \multicolumn{2}{c}{ Cells $\left(\times 10^{6}\right)$} \\
\cline { 2 - 3 } & Macrophages & Neutrophils \\
\hline Saline & $2.6(0.4)^{\star}$ & $0.1(0.0)$ \\
Leachate & $7.2(0.7)$ & $1.3(0.4)$ \\
Woouiv to 2.5 mg wool dust $\mathrm{M})$ & $10.3(1.2)$ & $3.0[0.4)$ \\
Endotoxin $(2.5 \mu \mathrm{g})$ & $5.5(0.5)$ & $0.6(0.1)$ \\
\hline
\end{tabular}

$\star_{\overline{\mathbf{X}}} \pm \mathrm{SEM} ; \mathrm{n}=$ three rats. 
Table 2 Chemotactic activity in wool dust $M$ leachate. No significant increase in chemotaxis with leachate compared with saline alone

\begin{tabular}{|c|c|c|c|}
\hline & \multicolumn{3}{|c|}{$\begin{array}{l}\text { Chemotaxis } \\
\text { (Migrated cells/high power field) }\end{array}$} \\
\hline & Saline & Wool dust leachate & $Z A S^{\star}($ Pos control $)$ \\
\hline Experiment 1 & $0.4(0.7) \dagger$ & $0(0)$ & \multirow{2}{*}{$86 \cdot 3(11 \cdot 8)$} \\
\hline Experiment 2 & $1 \cdot 2(1 \cdot 2)$ & $0(0)$ & \\
\hline
\end{tabular}

*Zymosan activated serum.

$\dagger($ SEM $)$ of 10 high power fields on two filters.

chemokinetic activity was present in the activated serum most of the migration was true chemotaxis.

\section{EPITHELIAL INJURY CAUSED BY DUST FROM WOOL}

\section{MILLS}

Figure 3 shows that the leachate from wool mill ledge dust was capable of causing direct epithelial injury of both the lytic and detachment type. Lysis was present to the greatest extent in neat and 1/10 dilutions whereas detachment was present at all concentrations even down to $1 / 100$, with some samples of dust $\mathrm{E}$ showing pronounced activity at this dilution. Detachment and lysis were also caused, whether the dust was leached into fluid lavaged from rat lung or into medium. On the whole, dust $M$ caused more measurable detachment to epithelial cells than dust $E$ with an average of $5 \cdot 1$-fold more detachment with undiluted leachate compared with control ( $\mathrm{p}<0.05)$; dust $\mathrm{E}$ by comparison showed an average of $2 \cdot 1$-fold more detachment than the medium control. Detachment is underestimated in cases where there are high concentrations of lysis as with dust $\mathrm{E}$, since lysed cells are not available for detachment. Dust E was most toxic causing more lysis, 2.9-fold more than control with the undiluted leachate $(p<0.05)$ whereas this figure was 1.9 for dust $M$. Significant increases in detachment were also caused by dust $\mathrm{E}$ at $1 / 10$ and $1 / 100$ dilution $(\mathrm{p}<0.05)$.

\section{Discussion}

The most obvious response in rat lungs to instilled wool mill dust was acute inflammation. The inflammation was short lived, since, despite the fact that a considerable insult of $2.5 \mathrm{mg}$ of dust was used, the bronchoalveolar lavage cellular profile had returned to near normal by day 7 . Presumably daily inhalation exposure to wool dust would result in chronic inflammation, though we have not investigated this. In addition to inflammation an immune response was suggested by the presence of aggregates of leukocytes, peaking at seven days after exposure. We have not observed this response with any of the mineral dusts we have tested previously using a similar assay system. A continuing immune response in the alveolar region could contribute to chronic inflammation through immune complex mediated injury in the case of humoral immunity or, in the case of a cell mediated immune response, lymphokine mediated inflammation. The presence of persistently, although modestly, increased free lymphocytes in the bronchoalveolar lavage tends to support the idea that the immune system is affected. The type(s) of cells comprising the clumps was not ascertained but is to be the object of further study. A parallel study of the effects of wool dust on the immune system will be reported separately.

The inflammation caused by the wool dusts was not due simply to a phagocytic burden since $\mathrm{TiO}_{2}$ was substantially less active than wool mill dust. We investigated two possible mechanisms whereby wool mill dusts could have generated inflammation; $(a)$ endotoxin, or some other component within the dust, could possess chemotactic activity or directly activate the complement cascade to generate chemotaxins; $(b)$

Table 3 Generation of chemotactic activity by the action of wool dust on rat serum. Significant $(p<0.01)$ increase in chemotaxis with wool treated serum compared with control serum

\begin{tabular}{|c|c|c|c|c|}
\hline & \multicolumn{4}{|c|}{$\begin{array}{l}\text { Chemotaxis } \\
\text { (Migrated cells/high power field) }\end{array}$} \\
\hline & Control serum & Wool treated serum & $Z A S^{\star}($ Pos control $)$ & Chemokinesis \\
\hline Experiment 1 & $23.9(3.2) \dagger$ & $61.4(8.0)$ & \multirow{2}{*}{$86 \cdot 3(11 \cdot 8)$} & $16.9(6.5)$ \\
\hline Experiment 2 & $31.9(5 \cdot 7)$ & $62 \cdot 3(9 \cdot 4)$ & & $12 \cdot 3(3 \cdot 2)$ \\
\hline
\end{tabular}

$\star$ Zymosan activated serum.

$\dagger \overline{\mathbf{x}}($ SEM $)$ of 10 high power fields on two filters. 

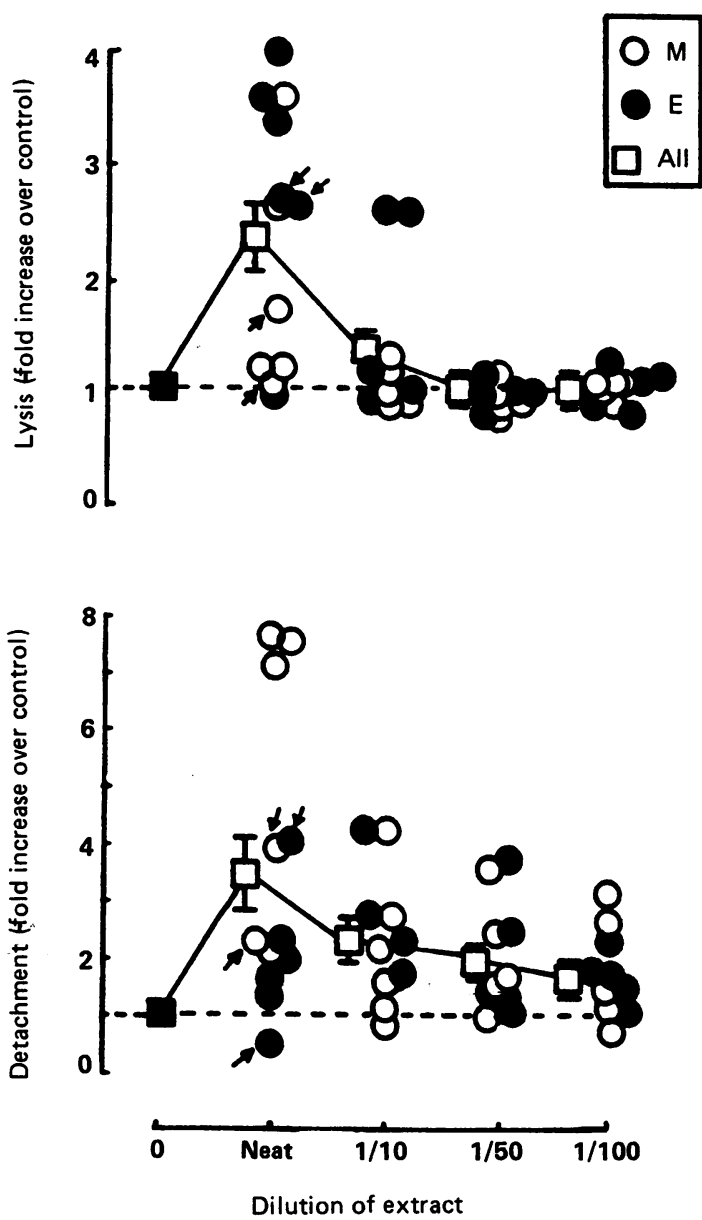

Figure 3 Alveolar epithelial cell-lysis (upper panel) and detachment (lower panel) shown by extracts of dust from mill $M$ (open circles) and mill $E$ (closed circles). Results from six (undiluted) or five (other dilutions) separate experiments. Arrows denote experiments where diluted lung lavage fluid was used for extraction. Squares show mean \pm SEM from all data at that dilution. Black squares and dotted line represent unity - that is, spontaneous detachment or lysis-all data obtained as

\section{cpm in presence of wool extract}

cpm spontaneous.

See results section for statistical analysis

component(s) of the wool mill dust could injure epithelial cells. Wool mill dust samples possessed no intrinsic chemotactic activity but did activate complement and injure epithelial cells in vitro. The potential role of endotoxin in causing these inflammatory/immune effects in the lungs of workers and rats exposed to wool dust deserves attention because of its inflammatory activity ${ }^{10}$ and because endotoxin was present in other samples of wool mill dust collected from the air of the mills studied here. ${ }^{1}$ Endotoxin may contribute to the respiratory symptoms observed in workers from a variety of industries exposed to airborne dusts ${ }^{11}$ and has been implicated $\stackrel{\mathbb{P}}{\stackrel{0}{\circ}}$ in symptoms such as those of byssinosis in workers in a wool carpet factory in Turkey. ${ }^{12}$

Some, but not all, of the inflammatory activity of $\bar{C}$ the wool dust could be accounted for by soluble $\underline{\underline{E}}$ components that could be leached into saline. Some $\frac{\bar{\rho}}{\bar{T}}$ of this leached material could have been endotoxin $\propto$ but a relatively large dose of endotoxin $(2.5 \mu \mathrm{g})$ was not very active in causing inflammation in the rat $\vec{A}$ lung. This was a commercially obtained sample of endotoxin, however, and may not have been $\vec{\omega}$ representative of the endotoxin in the samples of the $O$ wool mill dust. Endotoxin may also have been $\mathbb{\mathbb { D }}$ involved in the generation of chemotaxins in serum. $?$

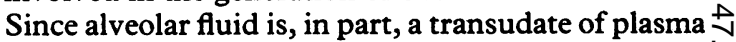
and contains complement, ${ }^{13}$ then wool dust deposit- $\vec{t}$ ing in the lung could activate complement leading to inflammation.

Our finding that a soluble product from wool mill 은 ledge dust caused both lysis and detachment of $\vec{\rightarrow}$ epithelial cells indicates another possible mechanismo by which wool dust could contribute to inflammation. Epithelial injury is a powerful stimulus to $\vec{\theta}$ inflammation, since dead cells are chemotactic and? exposed basement membrane activates com- $\square$ plement. ${ }^{14}$

The dust collected from the carding room $(M)$ was the most active of the dusts in causing inflammation; the backwinding dust the least. Since the three dusts $\mathbb{D}$ were collected from different factories we cannot be $\underset{\vec{F}}{\overrightarrow{2}}$ sure that these differences are related to the stages of the manufacturing process rather than the differen- $\frac{J}{\sigma}$ ces between the factories. Size distribution could be important in determining what mass of dust reaches the alveoli and is phagocytosed. In this respect the $\mathbb{\varnothing}$ ranking of activity exactly follows the ranking of the dusts with regard to particle size. The proportions by $\frac{5}{3}$ mass of fine (respirable) dust in each sample were $M-$ $21 \cdot 8 \%, \mathrm{~S}-16 \cdot 6 \%$, and $\mathrm{E}-10 \cdot 4 \%{ }^{2}$ Since the dusts in $\mathrm{O}$ this study were instilled, however, aerodynamic behaviour is unlikely to influence deposition of the $\frac{}{5}$ dusts and increased particle number per unit mass in $\frac{D}{0}$ the finer dusts is a more likely explanation for the differences in inflammatory response.

This predominantly inflammatory response to wool mill dust is broadly consistent with what is 0 known of dust related illness in wool textile workers. $\omega$ The symptoms we found to be associated with exposure to dust in workers in the industry includedo conjunctivitis, rhinitis, chronic bronchitis, and wheeze. There was little evidence that wool dust $\stackrel{?}{?}$ caused asthma, the most dramatic allergic reaction in $\frac{T}{0}$ the lung, and atopic individuals were not more $\frac{\overrightarrow{+}}{0}$ susceptible to symptoms related to wool dust than $\cong$ other subjects. ${ }^{3}$ There was no evidence on the chest $\stackrel{\AA}{\Omega}$ radiographs of lung fibrosis or alveolitis. Lung functional deficits have not so far been convincingly 0 shown to be related to exposure to wool dust, though응 
we do not consider this possibility to have been excluded. ${ }^{3}$

Thus the symptoms conform to what is called "non-specific" lung disease, analogous to the chronic bronchitis associated with smoking, air pollution, ${ }^{15}$ and exposure to coalmine dust ${ }^{16}$ and some other industrial dusts, including organic dusts such as grain dust. ${ }^{17}$ The mechanisms of this non-specific response are not well understood, but inflammatory cell recruitment has been reported in the lung lavage of subjects with chronic bronchitis ${ }^{18}$ and in smokers ${ }^{19}$ and rats exposed experimentally to coalmine dust. ${ }^{20}$ Experimental studies similar to those described in the present paper have been carried out with grain dust in view of its ability to cause bronchitis. ${ }^{6}$ This study showed that the grain dust had strong inherent chemotactic activity for neutrophils which we did not find in the wool dust sample we tested; however, like wool dust, grain dust had powerful ability to activate complement and also caused alveolar macrophages to release neutrophil chemotaxins. Grain dust was not tested for ability to injure epithelial cells but cotton bract extract has been found to directly injure epithelial cells ${ }^{4}$ and to activate complement. ${ }^{5}$ Thus wool dust may be seen as generally fitting into the pattern of activity shown by other organic dusts with multiple non-specific effects on the pulmonary epithelium and leukocyte populations that result in inflammation in the airways.

Exposure to inorganic industrial dusts has been reported to cause recruitment of macrophages and neutrophils to the lungs of workers and experimentally exposed rats. ${ }^{21-23}$ Exposure to these dusts is associated in the long term with structural changes in the lung parenchyma and airways that include fibrosis, small airways disease (in response to asbestos), and possibly emphysema in response to coal dust. The non-specific effects of these dusts have received attention and they have been found to activate complement ${ }^{7}$ and injure macrophages. ${ }^{24}$ The ability of inorganic mineral dusts to cause pronounced parenchymal lung disease (fibrosis and emphysema) while wool mill dust injury appears to be confined to the airways could be related to $(a)$ the size of the dust, with more small dust particles depositing in the alveoli in the case of inorganic dusts or $(b)$ the non-biodegradability of natural mineral dusts causing increased leukocyte activation in the alveolar region.

The study was conceived as a preliminary approach to understanding the biological potential of whole unfractionated respirable dust collected from the air of wool mills. The study showed that this dust has the ability to cause inflammation in the rat lung in excess of that caused by a phagocytic stimulus alone $\left(\mathrm{TiO}_{2}\right)$. In relation to pulmonary disease in wool workers, we would suggest that if airborne wool mill dust is inhaled regularly in sufficient quantities it could cause epithelial injury in the airways or respiratory zone so contributing to inflammation. In addition complement could be activated by the dust, causing some recruitment via $\mathrm{C} 5 \mathrm{a}$ and also coating the wool dust particles with C3b. Macrophages may thereby be stimulated through their complement receptors to release chemotaxins and other mediators leading to further leukocyte recruitment. A combination of epithelial injury generated inflammation and leukocyte recruitment via complement activation could lead to further epithelial injury due to the injurious effects of the leukocytes themselves. ${ }^{8}$ The involvement of the specific immune response could also be a factor in enhancing inflammation.

No attempt has been made to characterise this complex mixture of materials likely to be present in the dust but further work is in progress.

This research was funded by the Health and Safety Executive.

1 Love RG, Smith TA, Jones CO, Gurr D, Soutar CA, Seaton A Respiratory symptoms in wool textile workers. $A n$ epidemiological study of respiratory health in west Yorkshire wool textile mills. Edinburgh: Institute of Occupational Medicine, 1986. (Tech memo TM/86/04.)

2 Love RG, Donaldson K, Cullen RT, et al. Further studies on respiratory health in wool textile workers. Edinburgh: Institute of Occupational Medicine, 1988. (Report TM/88/16.)

3 Love RG, Smith TA, Gurr D, Soutar CA, Scarisbrick DA, Seaton A. Respiratory and allergic symptoms in wool textile workers. Br J Ind Med 1988;45:727-41.

4 Ayars GH, Altman LC, O'Neil CE, Butcher BT, Chi EY. Cotton dust-mediated lung epithelial injury. $J$ Clin Invest 1986;78:1579-88.

5 Mundie TG, Boackie RJ, Ainsworth SK. In vitro alternative and classical activation of complement by extracts of cotton mill dust: a possible mechanism of byssinosis. Environ Res 1983;32:47-56.

6 Von Essen SG, Robbins RA, Thompson AB, Ertl RF, Linder J, Rennard S. Mechanisms of neutrophil recruitment to the lung by grain dust exposure. Am Rev Respir Dis 1988;138:921-7.

7 Donaldson K, Slight J, Johnston PP, Bolton RE, Seaton A. Production of alveolar macrophage chemotaxins by the action of pathogenic mineral dusts or serum from control rats and rats with inflammation. Thorax 1987;42:748-9.

8 Donaldson K, Slight J, Brown GM, Bolton RE. The ability of inflammatory bronchoalveolar leukocyte populations elicited with microbes or mineral dusts to injure alveolar epithelial cells and degrade extracellular matrix in vitro. Br J Exp Pathol 1988;69:327-38.

9 Snella MC, Rylander R. Endotoxin inhalation induces neutrophil chemotaxis by alveolar macrophages. Agents and Actions 1985;16:522-6.

10 Issekutz AL, Megyeri P, Issekutz TB. Role for macrophage products in endotoxin-induced polymorphonuclear leukocyte accumulation during inflammation. Lab Invest 1987;56:49-59.

11 Rylander R, Vesterlund J. Airborne endotoxins in various occupational environments. In: Endotoxins and their detection with the limulus amebocyte lysate test. New York: Alan R Liss, 1982:399-409.

12 Ozesmi M, Aslan H, Hillerdal G, Rylander R, Ozesmi C, Baris YI. Byssinosis in carpet weavers exposed to wool contaminated with endotoxin. $\mathrm{Br} J$ Ind $\mathrm{Med}$ 1987;44:479-83.

13 Warheit DB, George G, Hill LN, Snyderman R, Brody AR. Inhaled asbestos activates a complement-dependent chemoattractant for macrophages. Lab Invest 1985;52:505-14.

14 Pickrell JA. Sequence of events in pulmonary injury. In: Pickrell $\mathrm{JA}$, ed. Lung connective tissue: location, metabolism and response to injury. Baton Rouge: CRC Press, 1981:124-30.

15 Seaton A, Seaton D, Leitch AG. Crofton and Douglas's respiratory diseases. 4th ed. Oxford: Blackwell, 1989.

16 Rae S, Walker DD, Attfield MD. Chronic bronchitis and dust 
exposure in British coalminers. In: Walton WH, ed. Inhaled particles III. Old Woking, Surrey: Unwin Bros, 1971:873-81.

17 Dosman JA, Cotton DJ, Graham BL, Li KYR, Froh F, Barnett D. Chronic bronchitis and decreased forced expiratory flow rates in lifetime non-smoking grain workers. Am Rev Respir Dis 1980;121:11-6.

18 Martin TR, Raghu G, Maunder J, Springmeyer SC. The effects of chronic bronchitis and chronic air-flow obstruction on lung cell populations recovered by bronchoalveolar lavage. Am Rev Respir Dis 1985;132:254-60.

19 Hoidal JR, Niewoehner DE. Pathogenesis of emphysema. Chest 1983;83:679-85.

20 Donaldson K, Bolton RE, Brown DM, et al. Studies on the cellular response in lung tissue to the inhalation of mineral dust. Edinburgh: Institute of Occupational Medicine, 1988. (Report TM/88/01.)

21 Gellert AR, Langford JA, Winter RJD, Uthayakumar S, Sinha G, Rudd RM. Asbestosis: assessment by bronchoalveolar lavage and measurement of pulmonary epithelial per- $\stackrel{\overparen{D}}{S}$ meability. Thorax 1985;40:508-14.

22 Donaldson K, Bolton RE, Jones AD, et al. Kinetics of the $\overrightarrow{\bar{F}}$ bronchoalveolar leukocyte response in rats following exposure $\stackrel{\oplus}{\longrightarrow}$ to equal airborne mass concentrations of quartz, chrysotile asbestos, or titanium dioxide. Thorax 1988;43:525-33.

23 Voisin C, Wallaert B, Aerts C, Grosbois JM. Bronchoalveolar lavage in coalworkers' pneumoconiosis: oxidant and $\overline{\bar{s}}$ antioxidant activities of alveolar macrophages. In: Beck EG, $\vec{\Phi}$ Bigron J, eds. In vitro effects of mineral dusts. Berlin: Springer $\varrho$ Verlag, 1985:93-100.

24 Donaldson K, Brown GM. Assessment of mineral dust cytotox- $\mathcal{C}$ icity towards rat alveolar macrophages using a ${ }^{51} \mathrm{Cr}$ release $\overrightarrow{0}$ assay. Fundam Appl Toxicol 1988;10:365-6.

Accepted 17 July 1989

\section{Vancouver style}

All manuscripts submitted to the $\mathrm{Br} J$ Ind $\mathrm{Med}$ should conform to the uniform requirements for manuscripts submitted to biomedical journals (known as the Vancouver style)

The $\mathrm{Br} J$ Ind Med, together with many other international biomedical journals, has agreed to accept articles prepared in accordance with the Vancouver style. The style (described in full in Br Med J, 24 February 1979, p 532) is intended to standardise requirements for authors.

References should be numbered consecutively in the order in which they are first mentioned in the text by Arabic numerals above the line on each occasion the reference is cited (Manson ${ }^{1}$ confirmed other reports $\left.{ }^{2-5} \ldots\right)$. In future references to papers submitted to the $\mathrm{Br} J$ Ind Med should include: the names of all authors if there are six or less or, if there are more, the first three followed by et al; the title of journal articles or book chapters; the titles of journals abbreviated according to the style of Index Medicus; and the first and final page numbers of the article or chapter.

Examples of common forms of references are:

1 International Steering Committee of Medical Editors. Uniform requirements for manuscripts submitted to biomedical journals. Br Med J 1979;1:532-5.

2 Soter NA, Wasserman SI, Austen KF. Cold urticaria: release into the circulation of histamine and eosino-phil chemotactic factor of anaphylaxis during cold challenge. $N$ Engl J Med 1976;294:687-90.

3 Weinstein L, Swartz MN. Pathogenic properties of invading micro-organisms. In: Sodeman WA Jr, Sodeman WA, eds. Pathologic physiology: mechanisms of disease. Philadelphia: W B Saunders, 1974:457-72. 